\section{Occurrence of gastro- esophageal reflux on induction of anaesthesia does not correlate with the volume of gastric contents}

Jean-François Hardy MD FRCPC, Yves Lepage PhD, Nathalie Bonneville-Chouinard
In an attempt to explain the discrepancy between the high number of patients said to be at risk of aspiration pneumonitis and the low reported incidence of this anaesthetic complication. I00 ASA physical status I-II elective surgical patients were studied. The volume of fluid present in the stomach at the time of induction of anaesthesia was correlated with gastroesophageal reflux (GER) detected by visual inspection of the pharynx and by continuous measurement of upper oesophageal pH. Mean gastric volume was $30 \pm 28 \mathrm{ml}$ (range $0-210 \mathrm{ml}$ ). Gastric fluid volume $\geq 0.4 \mathrm{ml} \cdot \mathrm{kg}^{-1}$ at $\mathrm{pH} \leq 2.5$ was present in 46 patients. No GER was detected during induction of anaesthesia in our sample of 100 patients. Furthermore, patient age, duration of preoperative fasting, body mass index, cigarette smoking. alcohol consumption, preoperative anxiety, and a history of preoperative GER were not correlated with significant modifications of gastric volume or $\mathrm{pH}$. We conclude that the low incidence of aspiration pneumonitis in elective surgical patients may be explained in part by the very low risk of GER, despite gastric fluid volumes of more than $0.4 \mathrm{ml} \cdot \mathrm{kg}^{-1}$ in a high proportion of this patient population.

Dans le but d' expliquer la divergence apparente entre le nombre élevé de patients dits à risque de pneumonie d'aspiration et l'incidence faible de cette complication telle que rapporrée dans la littérature anesthésique, nous avons étudié 100 patients de

\section{Key words}

COMPLICATIONS: aspiration;

GASTROINTESTINAL TRACT: gastric $\mathrm{pH}$, gastric volume, gastroesophageal reflux.

From the Department of Anaesthesia, and the Department of Mathematics and Statistics, University of Montreal,

Montreal, Quebec.

Address correspondence to: Dr. Jean-François Hardy, Department of Anaesthesia, Maisonneuve-Rosemont Hospital, 5415 boul. l'Assomption, Montreal, Quebec, H1T 2M4. statut physique ASA I-II. Nous avons tenté d'établir une corrélation entre le volume du liquide présent dans l'estomac au moment de l'induction de l'anesthésie et la survenue de reflux gastro-cesophagien démontré par inspection laryngoscopique intermittente du pharynx et mesure continue du pH asophagien supérieur. Le volume moyen du liquide gastrique était de $30 \pm 28 \mathrm{ml}$ (de 0 à $210 \mathrm{ml}$ ). Quarante-six patients avaient un volume de liquide gastrique $\geq 0.4 \mathrm{ml} \cdot \mathrm{kg}^{-1}$ à un $\mathrm{pH} \leq 2,5 \mathrm{et}$ étaient donc théoriquement à risque de pneumonie d' aspiration. Aucun épisode de reflux gastro-asophagien n'a été détecté chez nos 100 patients. De plus, nous n' avons noté aucune corrélation entre le volume on le pH du résidu gastrique et l'âge des patients, la durée du jeûne pré-opératoire, le degré d'embonpoint, le tabagisme, la consommation d'alcool, l'anxiété pré-opératoire ou une histoire de reflux gastro-cesophagien pré-existant. Nous en venons à la conclusion que la faible incidence de pneumonie $d$ 'aspiration chez les patients opérés sur une base élective s'explique, en partie du moins, par le rique très faible de reflux gastro-cesophagien el ce, malgré un volume du résidu gastrique $\geq 0.4 \mathrm{ml} \cdot \mathrm{kg}^{-1}$ chez une grande proportion de ces patients.

In 1974, Roberts and Shirley, in an article on the prevention of acid aspiration during Caesarean section, "arbitrarily defined the patient at risk as that patient with at least $25 \mathrm{ml}$ of gastric juice of $\mathrm{pH}$ below 2.5 in the stomach at delivery." While it was clearly mentioned that this was a statement based on preliminary unpublished work in the rhesus monkey, this definition of risk rapidly gained widespread recognition and has only recently been disputed. ${ }^{2,3}$ According to this definition, 16 to 60 per cent of elective adult patients, ${ }^{4,5} 76$ per cent or more of paediatric patients, ${ }^{6} 75$ per cent of obese patients ${ }^{7}$ and 27 to 73 per cent of pregnant or post-partum patients $^{1.5}$ are said to be at risk of aspiration pneumonitis during anaesthesia.

Estimating the incidence of aspiration pneumonitis between one to six per 10,000 surgical cases, ${ }^{8-11}$ the 
above risk criteria lack the specificity to identify those patients effectively at risk of regurgitating and sustaining severe pulmonary injury. Identification of the patient population effectively at risk (or not at risk) appears warranted since conduct aimed at preventing gastroesophageal reflux (GER) and subsequent aspiration entails its own share of complications. For example, a "crash induction" with thiopentone and succinylcholine or an awake intubation is not usually considered the ideal anaesthetic for a patient with limited coronary reserve. ${ }^{12}$

This discrepancy between anticipated and observed morbidity arose when the proposed risk criteria were extended to predict the occurrence of aspiration pneumonitis, instead of confining them to the prediction of pulmonary damage following the actual passage of gastric fluid into the lungs. The current approach of estimating the risk of aspiration pneumonitis puts aside a multiplicity of factors that can play a critical role in the pathogenesis (or prevention) of this complication, especially the protective role of the lower oesophageal sphincter (LOS) in the prevention of reflux and subsequent aspiration. ${ }^{3}$ In a recent experiment assessing the risk of regurgitation in the cat (this animal provides a good model of the human LOS), Plourde et al. determined that the residual gastric volume needed to produce regurgitation under general anaesthesia was at least 20 times greater than the estimated volume required to produce pulmonary damage by direct intratracheal injection. ${ }^{13}$

While extrapolation requires caution, it is reasonable to suggest that the same may apply to humans and that this could explain the low predictive value of current risk criteria for aspiration pneumonitis. We undertook this study to determine the relationship between the volume of gastric contents and the incidence of regurgitation during induction of anaesthesia in 100 patients scheduled for an elective surgical procedure. We also attempted to verify whether factors known to increase gastric residue or decrease barrier pressure (Table I) increased the incidence of regurgitation in these patients.

\section{Methods}

The overall plan was to monitor regurgitation during induction of anaesthesia and correlate its occurrence with known or proposed risk factors.

After giving informed consent, 100 patients were studied according to a protocol approved by the hospital ethics committee. Patients aged over 18, ASA physical status I or II, and scheduled for elective surgery and general anaesthesia with tracheal intubation were included. Patients taking medications known to affect gastric secretion or LOS tone, patients with a nasogastric tube in place, patients having a pathologically increased gastric residue (e.g., pyloric stenosis, intestinal occlusion), and
TABLE I Factors associated with an incrcased risk of regurgitation during anaesthesia, either because of an increased residual gastric volume, or becausc of a decreased barrier pressure (LOS pressure minus intragastric pressure)

\begin{tabular}{ll}
\hline Factors affecting: & Expected effect \\
\hline $\begin{array}{l}\text { Residual gastric volume } \\
1 \text { Obesity }\end{array}$ & $\begin{array}{l}\text { Increased volume } \\
\text { Increased volume }\end{array}$ \\
2 Preoperative anxiety & Increased volume \\
3 Duration of preoperative fast & \\
LES tone & Decreased tonc \\
1 Alcohol consumption & Decreased tone \\
2 Smoking & Decreased tone \\
3 Symptoms of GER & \\
Intragastric pressure & \\
1 Obesity & Increased pressure \\
2 Intragastric volume $>1 \mathrm{~L}$ in adults & Increased pressure \\
\hline
\end{tabular}

those presenting for emergency surgery were excluded from the study.

All eligible patients were interviewed by a research assistant on the evening prior to surgery and baseline data were recorded. These included demographic data (age, sex, weight and height), smoking and drinking habits, and symptoms of GER. Body habitus was determined using the body mass index.$^{14}$ Patients who smoked 20 cigarettes or more a day at the time of interview were considered smokers. Consumption of alcoholic beverages was recorded as none, moderate (drinking related to social events), or regular (daily consumption). No other attempt was made to quantify intake of alcohol. Heartburn and acid regurgitation were considered evidence of GER. Again, no attempt was made to quantify the frequency or severity of these symptoms. In accordance with local practice, patients were fasted from midnight.

At 06:00 on the morning of surgery, all patients received premedication with sublingual lorazepam 2 $\mathrm{mg} \cdot 70 \mathrm{~kg}^{-1}$. Patients having surgery in the afternoon received a second dose of lorazepam at 12:00. Upon arrival in the waiting area of the operating room, patient anxiety was scored by the research assistant according to the following scale: 0 - no apprehension, may be asleep; 1 - slightly apprehensive but calm; 2 - worried, outspoken apprehensions; 3 - very anxious, agitated, crying.

On arrival in the operating room, routine monitors were attached to the patient. Diazepam $5 \mathrm{mg} \cdot 70 \mathrm{~kg}^{-1}$ plus sufentanil $10 \mu \mathrm{g} \cdot 70 \mathrm{~kg}^{-1}$ were administered IV to help the patient to tolerate insertion of the continuous $\mathrm{pH}$ monitor probe. While lying supine on the operating room table, after pharyngeal instillation of a few drops of lidocaine four per cent, the patient was instructed to swallow the $\mathrm{pH}$ monitor probe which was delicately inserted by the mouth. The probe (Microelectrodes Inc, 
ref. \#30750), approximately $2 \mathrm{~mm}$ in diameter, was positioned in the upper third of the oesophagus and taped at a depth of $20 \mathrm{~cm}$ from the incisor teeth. Prior to use for each experiment, the $\mathrm{pH}$ monitor (Beckman model 3500 , digital $\mathrm{pH}$ meter) was calibrated using standard controls, and the $\mathrm{pH}$ of the four per cent lidocaine solution was measured. The reference electrode was taped to the patient's shoulder.

The same anaesthetic technique was used for all patients. After receiving a defasciculating dose of $d$ tubocurarine $\left(50 \mu \mathrm{g} \cdot \mathrm{kg}^{-1}\right.$ ), the patient was allowed to breathe 100 per cent oxygen via a face mask for three minutes. Incremental sufentanil was then administered, for a total dose of $0.5 \mu \mathrm{g} \cdot \mathrm{kg}^{-1}$ (including sedation). Anaesthesia was induced with thiopentone $4 \mathrm{mg} \cdot \mathrm{kg}^{-1}$ followed by succinylcholine $1.5 \mathrm{mg} \cdot \mathrm{kg}^{-1}$ and, $60 \mathrm{sec}$ later, the trachea was intubated with a cuffed tracheal tube. Mask ventilation was avoided to prevent gastric insufflation. After ensuring proper positioning of the tracheal tube, the patient's lungs were ventilated with isoflurane 0.5 per cent in nitrous oxide 70 per cent and oxygen.

Two methods were used to detect regurgitation of gastric fluid. First, the investigator specifically searched for the presence of turbid fluid (suggestive of gastric fluid) in the pharynx at the time of tracheal intubation and at repeat examination five minutes later. A rigid laryngoscope using fibreoptic lighting and a Macintosh 3 blade (Heine Optotechnik) was used to ensure maximal visualisation. Second, $\mathrm{pH}$ of the upper third of the oesophagus was continuously measured and plotted on a Beckman strip chart recorder from the time of probe insertion to the beginning of surgery. A sudden decrease of oesophageal $\mathrm{pH}$ below four was considered evidence of regurgitation.

After the second laryngoscopy and before the beginning of surgery, stomach contents were aspirated through a large, vented, multi-orificed gastric tube (18 Fr Salem Sump tube, Argyle, St-Louis, MO). Our previous results show that the volume of aspirated gastric fluid, using this type of tube, is a good estimate of the total volume of gastric residue, and that dye dilution offers no advantage over aspiration. ${ }^{15}$ The volume and $\mathrm{pH}$ of fluid retrieved from the stomach were measured.

Neuromuscular blocking drugs were administered as required and reversed before awake extubation. Pulmonary complications were to be investigated in any patient regurgitating on induction of anaesthesia, using serial blood gas analysis and chest $x$-rays.

Statistical analysis was performed by the Department of Mathematics and Statistics. Descriptive statistics were obtained for each variable studied. All results are expressed as mean $\pm \mathrm{SD}$. Student's $t$ tests, analysis of variance, and linear regression analysis were used where

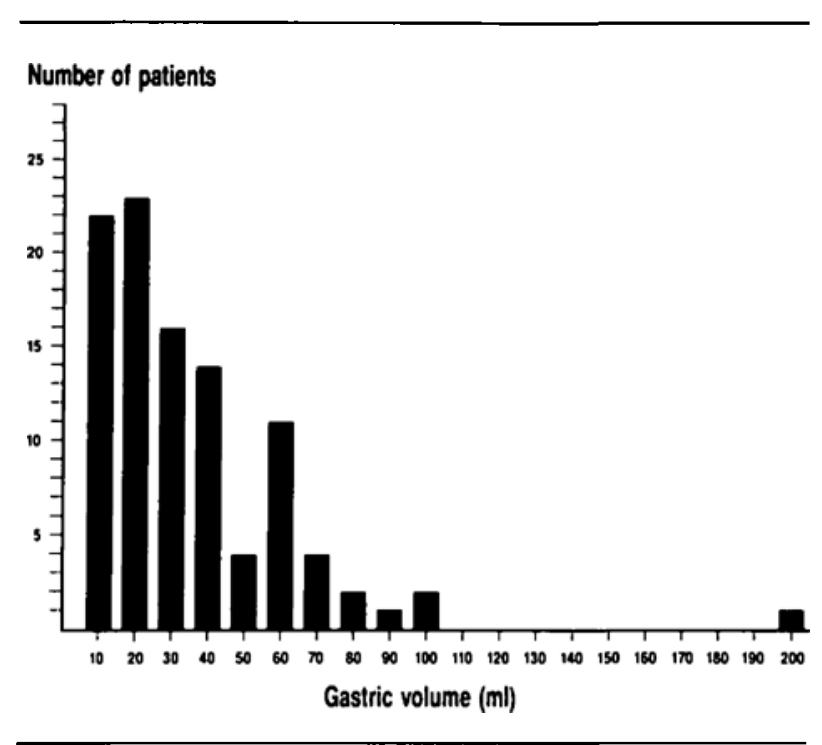

FIGURE 1 Distribution of gastric fluid volume.

appropriate. A $P<0.05$ was considered significant. Binomial distribution was used to compute the probabilities presented in Table IV.

\section{Results}

One hundred patients, aged $39 \pm 11$ yr (range 2l-64 yr), scheduled for elective orthopaedic ( $n=4)$, gynaecological $(n=59)$, general $(n=27)$, or genitourinary surgery $(n=10)$ were studied.

\section{Relationship between the volume of gastric contents and the incidence of regurgitation during induction of anaesthesia}

There was no direct evidence of regurgitation at the time of tracheal intubation and at repeat laryngoscopy five minutes later. A statistically significant decrease in mean $\mathrm{pH}$ occurred after awake control measurement of oesophageal $\mathrm{pH}$. Upper oesophageal $\mathrm{pH}$ was $5.66 \pm 0.71$ prior to induction (control), $5.58 \pm 0.71$ on induction of anaesthesia, $5.54 \pm 0.75$ at the time of intubation and $5.45 \pm$ 0.74 at the time of repeat laryngoscopy $(P<0.00001$ by ANOVA for repeated measures). Upper oesophageal $\mathrm{pH}$ was less than four in four patients at one time during the study period. These patients had pre-induction values $<5$, and gastric $\mathrm{pH}$ was at least $1.1 \mathrm{pH}$ units lower than the nadir of upper oesophageal $\mathrm{pH}$. Detailed study of all continuous $\mathrm{pH}$ recordings revealed a slow decline of upper oesophageal $\mathrm{pH}$ in all tracings. Upper oesophageal $\mathrm{pH}$ never decreased below 2.7 in any patient.

Gastric fluid had a volume of $30 \pm 28 \mathrm{ml}$ (range: $0-210$ $\mathrm{ml}$, Figure 1) and a $\mathrm{pH}$ of $1.9 \pm 1.13$ (range: $0.5-6.7$, Figure 2; no retrievable gastric fluid in five patients). 


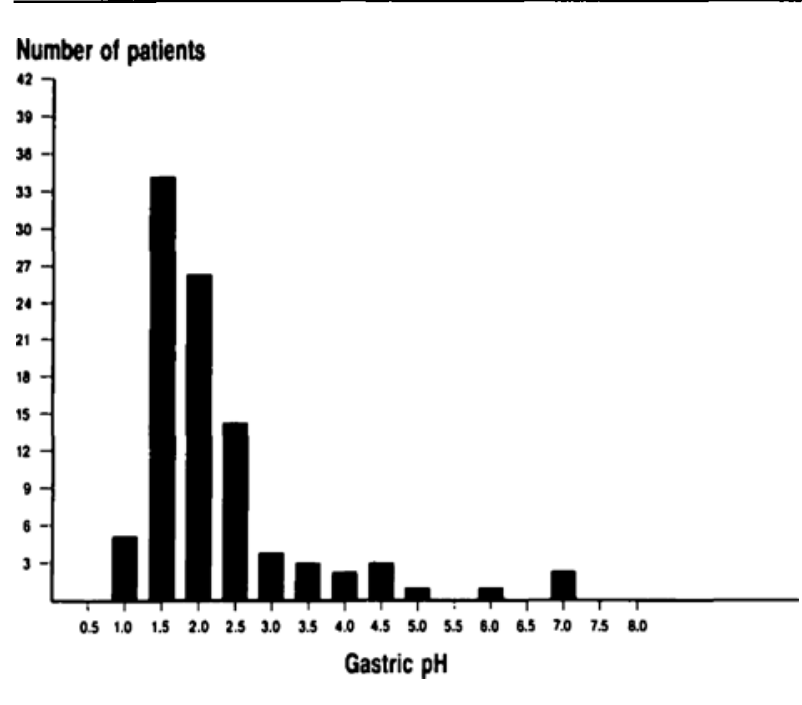

FIGURE 2 Distribution of gastric fluid pH.

Gastric fluid volume $\geq 0.4 \mathrm{ml} \cdot \mathrm{kg}^{-1}$ and $\mathrm{pH} \leq 2.5$ was found in 46 patients.

Gastric fluid $\mathrm{pH}$ was $>4$ in seven patients. In four patients the gastric $\mathrm{pH}$ was at least $0.8 \mathrm{pH}$ units lower than the nadir of upper oesophageal $\mathrm{pH}$. In the other three patients gastric $\mathrm{pH}(6.7,5.5$ and 6.6) was higher than the lowest upper oesophageal $\mathrm{pH}(5.2,5.1$ and 5.6 respectively). Gastric fluid volumes in these three patients were small $(9,8$ and $13 \mathrm{ml}$ respectively).

Since there was no evidence that any patient had effectively regurgitated on induction of anaesthesia, follow-up study of possible pulmonary complications was not performed.

\section{Effect of patient characteristics on GER}

In the absence of GER during the study period, this

TABLE II Gastric fluid volume and $\mathrm{pH}$ according to sex, smoking habits, and symptoms of GER

\begin{tabular}{llll}
\hline Group & $n$ & Volume & $p H$ \\
\hline Males & 22 & $32 \pm 20 \mathrm{ml}$ & $1.99 \pm 1.04$ \\
Females & 78 & $29 \pm 30 \mathrm{ml}$ & $1.87 \pm 1.16$ \\
$P$ & & 0.503 & 0.686 \\
& & & \\
Smokers & 43 & $29 \pm 33 \mathrm{ml}$ & $1.72 \pm 0.69$ \\
Non-smokers & 57 & $30 \pm 24 \mathrm{ml}$ & $2.04 \pm 1.37$ \\
$P$ & & 0.979 & 0.138 \\
GER symptoms & 28 & $26 \pm 20 \mathrm{ml}$ & $1.89 \pm 1.01$ \\
No GER symptoms & 72 & $31 \pm 31 \mathrm{ml}$ & $1.90 \pm 1.18$ \\
$P$ & & 0.400 & 0.951 \\
\hline
\end{tabular}

$n$ is the number of subjects. No statistically significant difference within each group (unpaired Student's test).
TABLE III Gastric fluid volume and $\mathrm{pH}$ according to body habitus, alcohol consumption and preoperative anxicty

\begin{tabular}{lrll}
\hline Group & $n$ & Volume & $p H$ \\
\hline Body habitus & & & \\
$B M I \leq 25$ & 61 & $26 \pm 23 \mathrm{ml}$ & $1.94 \pm 1.09$ \\
$25<\mathrm{BMI} \leq 30$ & 28 & $31 \pm 23 \mathrm{ml}$ & $1.87 \pm 1.29$ \\
$31<\mathrm{BMI}$ & 11 & $43 \pm 57 \mathrm{ml}$ & $1.75 \pm 1.03$ \\
$P$ & & 0.184 & 0.867 \\
& & & \\
Alcohol consumprion & & & \\
None & 39 & $31 \pm 22 \mathrm{ml}$ & $1.75 \pm 1.34$ \\
Moderate & 57 & $27 \pm 32 \mathrm{ml}$ & $2.02 \pm 1.07$ \\
Regular & 4 & $29 \pm 24 \mathrm{ml}$ & $1.70 \pm 0.55$ \\
$P$ & & 0.194 & 0.508 \\
& & & \\
Preoperastive anxiety & & & \\
No apprehension & 25 & $19 \pm 16 \mathrm{ml}$ & $1.64 \pm 0.55$ \\
Slight apprehension & 63 & $33 \pm 31 \mathrm{ml}$ & $2.00 \pm 1.28$ \\
Worricd patient & 8 & $36 \pm 28 \mathrm{ml}$ & $2.09 \pm 1.28$ \\
Agitated patient & 4 & $30 \pm 28 \mathrm{ml}$ & $1.50 \pm 0.81$ \\
$P$ & & 0.194 & 0.509 \\
\hline
\end{tabular}

$n$ is the number of subjects. No statistically significant difference within each group (one-way ANOVA).

relationship could not be directly examined. The relationship between patient characteristics and gastric fluid volume and $\mathrm{pH}$ are presented, given that the latter are considered primary determinants of the risk of GER and subsequent pulmonary complications.

There was no statistically significant difference in gastric fluid volume or $\mathrm{pH}$ between males and females, smokers and non-smokers, and patients symptomatic or not symptomatic of GER (Table II).

One-way analysis of variance was used to compare gastric fluid volume and $\mathrm{pH}$ according to different levels of BMI, preoperative anxiety, or alcohol consumption. There was no statistically significant difference within each group (Table III).

Duration of preoperative fasting was $14.9 \pm 2.9 \mathrm{hr}$ (range $10-23 \mathrm{hr}$ ). A statistically significant correlation between gastric fluid volume or $\mathrm{pH}$, and patient age or duration of fasting could not be demonstrated by simple linear regression analysis $\left(r^{2} \leq 5.5\right.$ in the four regressions studied).

\section{Discussion}

Aspiration pneumonitis is a potentially serious, but rare $^{8-11}$ complication of anaesthesia. Identification of the patient at risk has been attempted using gastric fluid volume and $\mathrm{pH}$ criteria while neglecting the risk of GER, without which aspiration pneumonitis as a complication of anaesthesia is impossible. This is the first attempt to correlate the occurrence of GER with the volume of fluid present in the stomach. In elective general surgical patients, the risk of GER on induction of anaesthesia 
TABLE IV Probability of obtaining $x$ cases of aspiration pncumonitis (in a sample of 100), given a known incidence of 3,5 or 6 in 10,000 anacsthetics

\begin{tabular}{llll}
\hline & $4 / 10,000$ & $5 / 10,000$ & $6 / 10,000$ \\
\hline$P(x=0)$ & 0.960782 & 0.951218 & 0.941748 \\
$P(x=1)$ & 0.038447 & 0.047585 & 0.056539 \\
$P(x=2)$ & 0.000762 & 0.001178 & 0.001680 \\
$P(x=3)$ & 0.000010 & 0.000019 & 0.000033 \\
$P(x>3)$ & 0.973450 & 0.235842 & 0.485308 \\
& $x 10^{-7}$ & $x 10^{-6}$ & $x 10^{-6}$ \\
\hline
\end{tabular}

appears to be negligible, despite gastric fluid volumes of more than $0.4 \mathrm{ml} \cdot \mathrm{kg}^{-1}$. It can be seen from Table IV that the probability of obtaining one case of significant aspiration pneumonitis (in a sample of 100 patients) is low. Moreover, this probability, based on a genuine incidence of $4-6$ cases per 10,000 anaesthetics, ${ }^{8-10}$ integrates numerous variables, not all of which were present in our patient population. These include: the characteristics of the gastric residue (volume and $\mathrm{pH}$ ), the fact that GER must occur and that sufficient gastric fluid must reach the lungs to cause parenchymal damage, and often a poor preoperative condition of the patient.

Most gastric volumes ranged from 0 to $93 \mathrm{ml}$ (one patient had a residue of $210 \mathrm{ml}$ ), and mean volume was comparable with those reported previously for inpatients (approximately $30 \mathrm{ml}){ }^{4,5,16}$ Higher $^{16}(69 \mathrm{ml})$, similar ${ }^{17}$ $(30 \mathrm{ml})$ or smaller ${ }^{18}(20.6 \mathrm{ml})$ mean gastric residues have been reported in unpremedicated outpatients. Thus, in accordance with our data, a large majority of elective surgical patients have gastric residues of less than $100 \mathrm{ml}$. It is of interest that retrieval of gastric fluid was performed after a standard (i.e., not a rapid sequence) induction of anaesthesia in all referenced studies and that no single case of GER or pulmonary complication was reported, despite subsequent inference that a large proportion of patients were "at risk."

Carmine red, an inert organic dye administered in the form of two $200 \mathrm{mg}$ gelatin capsules with 20 to $30 \mathrm{ml}$ of water, has been used to stain gastric secretions and facilitate the identification of regurgitated material. ${ }^{19,20}$ This method of detection was abandoned in the pilot phase of the present study because of the difficulty in swallowing the capsules and the unpredictable mixing with gastric contents when administered "on call." Careful inspection of the pharynx with the newer, brightly lighted, laryngoscopes was used instead and correlated with continuous $\mathrm{pH}$ monitoring. While GER of clear gastric fluid could have been missed, measurement of upper oesophageal pH refutes this possibility.

The existence of GER is established when variables of acid exposure ( $\mathrm{pH}<4$ ) exceed two standard deviations above the mean values for similar variables measured in asymptomatic control subjects. The commonly measured variables include: per cent time oesophageal $\mathrm{pH}<4$, number of GER episodes per hr, number of episodes per hr with $\mathrm{pH}<4$ that lasted longer than five minutes, and the longest duration of a GER episode. However, while reliably discriminating between subjects with and without GER, ambulatory 24-hr pH monitoring does not specifically determine if the patient's symptoms are due to GER, unless it is complemented by the recently described Symptom index. ${ }^{21}$

This definition of GER is not very useful to anaesthetists who are more concerned with the detection of GER which is capable of causing short-term pulmonary damage, rather than long-term reflux osophagitis. A critical minimal level of acidity of $\mathrm{pH}$ less than 2.5 is usually considered necessary to cause lung damage in most animal species ${ }^{22-25}$ and may be more appropriate for detecting GER of significance to the anaesthetist. Thus, despite an upper oesophageal $\mathrm{pH}$ of less than four in four patients, GER was ruled out by: the absence of an abrupt decrease of $\mathrm{pH}$ on continuous recordings, the oesophageal to gastric $\mathrm{pH}$ difference which kept detection of significant acidity possible, and an upper oesophageal $\mathrm{pH} \geq 2.7$.

A small but statistically significant decrease in upper oesophageal $\mathrm{pH}$ occurred after induction of anaesthesia from a value of 5.66 to a value of 5.45. Results of a similar study by Illing are in agreement with our observations. ${ }^{26}$ While such a small decrease of upper oesophageal $\mathrm{pH}$ is not indicative of GER, the cause of the phenomenon is unknown.

Aspiration of gastric contents containing small food particles at a pH of 5.9 has also been associated with hypoxia, hypercapnia, acidosis and pneumonitis in dogs. ${ }^{27}$ In the clinical setting, regurgitation of such material is most likely to occur when the stomach is full after meals, which is also the time when gastric $\mathrm{pH}$ is at its highest. ${ }^{25}$ Based on $\mathrm{pH}$ recordings, detection of GER in three patients was theoretically impossible since gastric $\mathrm{pH}$ was higher than oesophageal $\mathrm{pH}$. However, these patients had very small gastric residues and contamination of fluid during aspiration of stomach contents by saliva ( $\mathrm{pH}$ 6.0-7.0) or by lidocaine (measured $\mathrm{pH} \mathrm{6.7)} \mathrm{may}$ explain this unusual finding. Passage of the electrode into the stomach to measure $\mathrm{pH}$ directly was not performed to avoid disturbing normal lower oesophageal sphincter function and acid contamination of the oesophagus shortly before the study period.

Different patient populations are classically considered at risk of aspiration pneumonitis, based on body habitus or other characteristics. The present study attempted to 
correlate patient characteristics with the volume of gastric fluid present on induction of anaesthesia and the occurrence of GER. Obesity (previously defined as $50 \mathrm{~kg}$ over ideal body weight) is associated with moderately increased gastric residues, of the order of $40 \mathrm{ml} .{ }^{7}$ These volumes do not appear to place the obese patient at increased risk of GER, if a smooth induction of anaesthesia is ensured. Mask ventilation was avoided and difficulty with intubation was not encountered in this study. The influence of preoperative anxiety on gastric emptying is controversial. ${ }^{3}$ High levels of anxiety measured with a simple clinical scale, as opposed to formal psychological questioning, were not correlated with above normal gastric residues. Cigarette smoking is a common reversible cause of GER. ${ }^{28-30}$ The LOS pressure decreases shortly after smoking begins and returns towards normal minutes after stopping. ${ }^{28}$ Normal gastric residues and the unavoidable period of abstinence before surgery help to explain why GER was not increased in smokers. Similarly, acute ethanol ingestion induces oesophageal dysfunction and GER. ${ }^{31.32}$ While this may be important in intoxicated patients, the drinking history (often of doubtful validity) was not associated with GER in fasted patients.

The accurate evaluation of many proposed risk characteristics is often difficult and usually well beyond the scope of the typical preoperative visit. Besides, our results and those of a similar study question the relevance of these traditional risk factors in anaesthesia practice. ${ }^{26}$

This study was limited to the induction of anaesthesia for two reasons. First, once the trachea is intubated, the risk of aspiration greatly decreases. The liquid contents of the stomach may be emptied with a multi-orificed, vented tube and the patient may be extubated awake if aspiration is a concern for any other reason. Second, possible injury to the oesophagus in the presence of electrocautery was a serious concern. The protection afforded in the operating room, compared with the ward, by the patient isolation module of the $\mathrm{pH}$ meter could not be determined with sufficient certainty in our view.

In conclusion, the risk of GER during induction of anaesthesia in elective surgical patients is very low and is independent of patient characteristics. This provides a plausible explanation to the discrepancy between the high percentage of patients usually considered at risk of aspiration pneumonitis and the actual occurrence of this complication.

\section{References}

1 Roberts RB, Shirley $M A$. Reducing the risk of acid aspiration during cesarean section. Anesth Analg 1974; 53: 859-68.
2 Gibbs CP, Modell JH. Aspiration Pncumonitis. In: Miller RD (Ed.). Anesthesia, 2nd ed., New York: Churchill-

Livingstone Inc., 1986; 2023-50.

3 Hardy JF. Large volume gastroesophageal reflux: a rationale for risk reduction in the perioperative period. Can J Anacsth 1988; 35: 162-73.

4 Stoelting $R K$. Gastric fluid volume and $\mathrm{pH}$ after fentanyl, enflurane or halothane-nitrous oxide anesthesia with or without atropine or glycopyrrolate. Ancsth Analg 1980; 59: 287-90.

5 James CF, Gibbs CP, Banner T. Postpartum perioperative risk of aspiration pneumonia. Anesthesiology 1984; 6I: 756-9.

6 Coté CJ, Goudsouzian NG, Liu LMP, Dedrick DF, Szyfelbein SK. Assessment of risk factors related to the acid aspiration syndrome in pediatric patients - gastric $\mathrm{pH}$ and residual volume. Anesthesiology 1982; 56: 70-2.

7 Vaughan $R W$, Bauer $S$, Wise $L$. Volume and $\mathrm{pH}$ of gastric juice in obese patients. Anesthesiology 1975; 43: 686-9.

8 Tiret L, Desmonts JM, Hatton F, Vourc'h $G$. Complications associated with anaesthesia - a prospective survey in France. Can Anaesth Soc J 1986; 33: 336-44.

9 Cohen MM, Duncan PG, Pope WDB, Wollkenstein C. A survey of 112,000 anaesthetics at one teaching hospital. Can Anaesth Soc J 1986; 33: 22-31.

10 Olsson GL, Halllen B, Hambraeus-Jonzon K. Aspiration during anaesthesia: a computer-aided study of 185,358 anaesthetics. Acta Anaesthesiol Scand 1986; 30: 84-92.

11 Coombs $D W$. Aspiration pneumonia prophylaxis. Anesth Analg 1983; 62: 1055-8.

$12 O^{\prime}$ Connor JP, Wynands JE. Anesthesia for myocardial revascularization. In: Kaplan JA (Ed.). Cardiac Ancsthesia, 2nd ed., Philadelphia: W.B. Saunders Company, 1987: 551-88.

13 Plourde $G$, Hardy $J F$. Aspiration pneumonia: assessing the risk of regurgitation in the cat. Can Anaesth Soc $J$ 1986; 33: 345-8.

14 Stoelting RK, Dierdorf SF, McCammon RL. Anesthesia and Co-existing Disease. 2nd ed. New York: Churchill Livingstone, 1988.

15 Hardy JF, Plourde G, Lebrun M, Côté C, Dubé S, Lepage $Y$. Determining gastric contents under general anaesthesia: evaluation of two methods. Can J Anaesth 1987; 34: 474-7.

16 Ong BY, Palahniuk RJ, Cumming $M$. Gastric volume and pH in out-patients. Can Anacsth Soc J 1978; 25: 36-9.

17 Manchikanti L, Canella MG, Hohlbein $L$, Colliver $J A$. Assessment of effect of various modes of premedication on acid aspiration risk factors in outpatient surgery. Anesth Analg 1987; 66: 81-4. 
18 Sutherland AD, Maltby JR, Sale JP, Reid CRG. The effect of preoperative oral fluid and ranitidine on gastric fluid volume and pH. Can J Anaesth 1987; 34: 117-21.

19 Blitt CD, Gutman HL, Cohen DD, Weisman H, Dillon $J B$. "Silent" regurgitation and aspiration during general anesthesia. Anesth Analg 1970; 49: 707-12.

20 Turndorf $H$, Rodis ID, Clark TS. "Silent" regurgitation during general anesthesia. Anesth Analg 1974; 53: 700-3.

21 Wiener GJ, Richter JE, Copper JB, WuWC, Castell $D O$. The Symptom Index: a clinically important paramcter of ambulatory 24-hour csophageal pH monitoring. Am J Gastroenterol 1988; 83: 358-61.

22 Greenfield JL, Singleton RP, MCCafree DR, Coalson $J$. Pulmonary effects of experimental graded aspiration of hydrochloric acid. Ann Surg 1969; 170: 71-86.

23 Awe WC, Fletcher WS, Jacob SW. The pathophysiology of aspiration pneumonitis. Surgery 1966; 60: 232-9.

24 Teabaut JR. Aspiration of gastric contents: an experimental study. Amer J Pathol 1952; 28: 51-67.

25 Wynne J. Aspiration pncumonitis: correlation of experimental models with clinical disease. Clin Chest Med 1982; 3: 25-34.

26 Illing $L H$. Gastroesophageal reflux in anacsthetized patients. Can J Anacsth 1989; 36: S123-4.

27 Schwartz DJ, Wynne JW, Gibbs CP, Hood Cl, Kuck $E J$. The pulmonary consequences of aspiration of gastric contents at $\mathrm{pH}$ values greater than 2.5. Am Rev Respir Dis 1980; 121: 119-26.

28 Dennish GW, Castell DO. Inhibitory effect of smoking on the lower esophageal sphincter. N Engl J Med 197; 284: 1136-7.

29 Stanciu $C$, Bennet JR. Smoking and gastro-oesophageal reflux. Br Med J 1972; 3: 793-5.

30 Chattopadhyay DK, Greaney $M G$, Irvin TT. Effect of cigarette smoking on the lower oesophageal sphincter. Gut 1977; 18: 833-5.

31 Hogan WJ. Viegas de Andrade SR, Winship DH. Ethanolinduced acute esophageal motor dysfunction. J appl Physiol 1972; 32: 755-60.

32 Kaufman SE. Kaye MD. Induction of gastroesophageal reflux by alcohol. Gut 1978; 19: 336-8. 